Brit. J. industr. Med., 1952, 9, 80.

\title{
SIMPLIFIED EYE-PIECE GRATICULE FOR ASSESSING THERMAL PRECIPITATOR DUST SAMPLES
}

\author{
BY
}

\author{
H. H. WATSON
}

From the Pneumoconiosis Research Unit of the Medical Research Council, Llandough Hospital, Nr. Cardiff

(RECEIVED FOR PUBLICATION JUNE 12, 1951)

Microscope counting and sizing of dust particles, for example, on thermal precipitator records, are done with the aid of an eye-piece graticule (Fig. 1), usually that designed by Patterson and Cawood (1936). Modifications have been made by Fairs (1943) and by May (1945) in which the sizes of the comparison circles increase by a constant factor of $\sqrt{2}$, but such graticules have not been used by many workers.
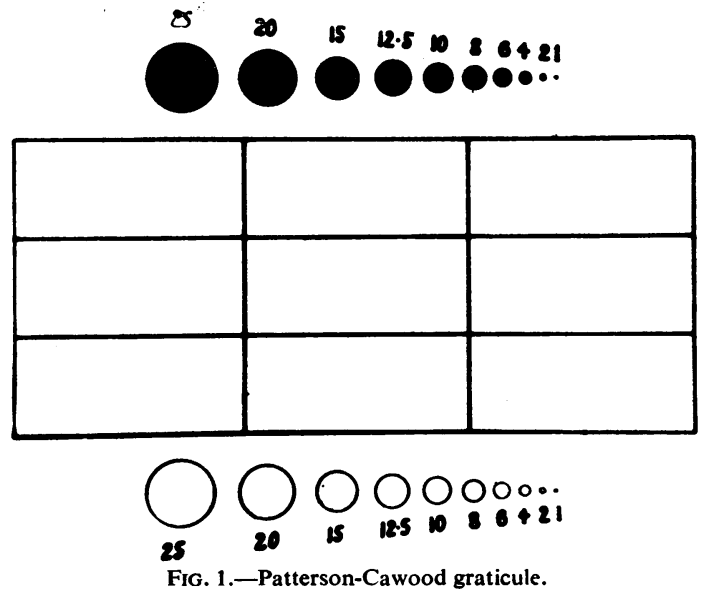

The Pneumoconiosis Research Unit, at the beginning of its dust assessment with the thermal precipitator, decided to use a particle number concentration within the restricted size-range of 0.5 to $5 \mu$ mean projected diameter as a measure of the hazardous fraction of air-borne coal-mine dust. Between 1947 and 1949 detailed size distributions were made with a Patterson-Cawood graticule, the cumulative size distributions being plotted on logarithmic probability paper. The percentage of particles within the restricted range was read off from the plot and the required number concentration determined. It also became our practice to quote particles per cubic centimetre (or percentages) within four size-groups

$$
<0.5 \mu, 0.5 \text { to } 2 \mu, 2 \text { to } 5 \mu,>5 \mu
$$

to give some indication of the fineness of the dust.

The information contained in the detailed sizing with the Patterson-Cawood graticule in $\mathbf{1 0}$ or more groups was rarely used, and, as the computing and graphical work required to produce the desired final result from the raw figures was considerable, a simplified procedure using a new three-spot graticule was developed. This graticule (Fig. 2) has been used in the eye-piece of an ordinary microscope and also on the screen of a Vickers projection microscope. It contains the conventional two rows of comparison circles, one row of open circles, and one row of black spots (filled-in circles), the individual circles being drawn with their diameters in the proportions of $5: 2: 0 \cdot 5$. In practice, by suitably altering the tube-length of the microscope, the magnification is adjusted so that when using a $2 \mathrm{~mm}$. objective the circles correspond with diameters of $5 \mu, 2 \mu$, and $0.5 \mu$ respectively.

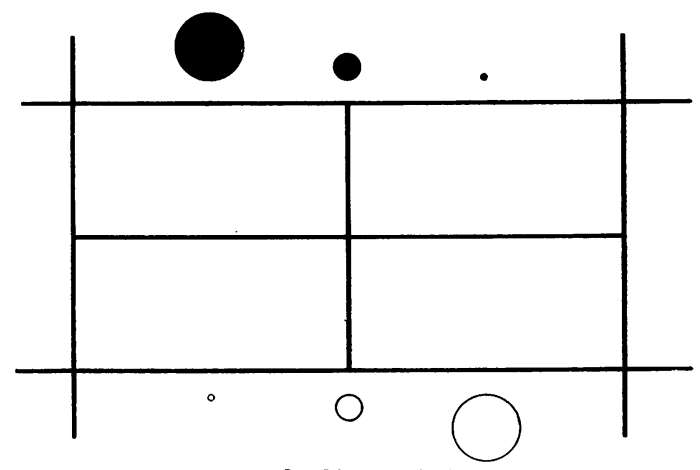

Fig. 2.-New graticule. 
The graticule rectangle is $3.8 \mathrm{~mm}$. long and 1.9 $\mathrm{mm}$. wide, the diameter of the large circle being one-eighth of the length of the rectangle. The open circles are drawn so that the diameters to the outside of the lines are equal to the diameters of the respective black spots. Thus, when the largest circle is set to correspond with $5 \mu$ diameter, the length of the rectangle of the graticule is $40 \mu$ and its width $20 \mu$. The short extensions of the rectangle lines have been found useful to guide the observer when a dust record is being traversed across the field of view.

The graticule has been used principally with Beck microscopes, the optical equipment of each consisting of a $2 \mathrm{~mm}$. oil-immersion objective and a $\times 17$ eye-piece. The working tube lengths of two such microscopes required to give the correct calibration are $162 \mathrm{~mm}$. and $170 \mathrm{~mm}$. respectively. It should be noted that the Beck $\times 17$ eye-piece is of the positive type in which the focal plane is below the field lens. With a Huygenian type of eye-piece the focal plane lies between the field and the eye lenses, the relative magnifications of the two depending on the make. With this type it is more difficult to arrange a suitable size of graticule to ensure correct calibration; generally a smaller size is required, one with long side of $3.1 \mathrm{~mm}$. being a suitable compromise for a number of microscope combinations that have been tested, in which a $\times 10$ or $\times 15$ Huygenian eye-piece is used in combination with a $2 \mathrm{~mm}$. $(\times 90)$ oil-immersion objective. A working tube length as much as 180 $\mathrm{mm}$. appears to be permissible for counting and sizing particles larger than $0.5 \mu$ diameter ; visibility of particles closer to the limit of visibility will, however, be poor under this condition (Beadle and Patterson, 1939). In binocular microscopes in which the tube length is fixed, additional tube length may be obtained by inserting a collar of suitable length in each eye piece tube.

For use with the Vickers projection microscope the graticule is reproduced on the ground-glass viewing screen. Allowing for an overall magnification of $\times 2,000$ (with a $2 \mathrm{~mm}$. objective) the large circle is $1 \mathrm{~cm}$. diameter. Line thicknesses are as follows :

$$
\begin{array}{llllll}
\text { Rectangle } & \ldots & \ldots & \ldots & \ldots & 0.02 \text { in. } \\
\text { Open circles } & \ldots & \ldots & \ldots & \ldots & 0.006 \text { in. }
\end{array}
$$

The lead-in or rectangle-extension lines are all $1 \mathrm{~cm}$. long.

It was considered essential in designing a new graticule for dust assessment work to make it as simple as possible. Thus, in an earlier design the figures $5 \mu, 2 \mu$, and $0.5 \mu$ were inscribed against the respective spots and circles, but these have been eliminated in the final design since they served no useful purpose.

When making a full size distribution with a Patterson-Cawood graticule it is necessary for the microscopist to be assisted by a recorder. The rate of counting (with recording) varies from observer to observer and with the type of dust deposit being assessed. Limits of counting rates for experienced microscopists vary from about one and a half to about three seconds per particle, with an average of about two seconds. With the three-spot graticule, when examination of the particles need not be so critical because of the wider size groups in which they are placed, the counting rate is usually about one second for each particle. With only four size groups in which to place particles it is a simple matter to use a key-board recorder. This practice is now standard, and it saves man power since the microscopist can himself record the count while looking down the microscope. The calculations necessary to produce the final result are few and simple, and no graphical work is needed resulting in a further saving of time compared with the old method.

TABLE 1

INCREASE IN PARTICLES CLASSIFIED IN FOUR SIZE GROUPS

\begin{tabular}{c|c|c}
\hline $\begin{array}{c}\text { Sample } \\
\text { No. }\end{array}$ & $\begin{array}{c}\text { Count } \\
\text { (no sizing) }\end{array}$ & $\begin{array}{c}\text { Count } \\
\text { (with sizing) }\end{array}$ \\
\hline 1 & 95 & 109 \\
\hline 2 & 99 & 115 \\
\hline 3 & 93 & 100 \\
\hline 4 & 67 & 76 \\
\hline 5 & 83 & 94 \\
\hline 6 & 201 & 214 \\
\hline
\end{tabular}

Other simple modifications of the original Patterson-Cawood graticule to meet specific requirements might be suggested. For instance, in order to count the number of particles between two size limits, such as 0.5 and $5.0 \mu$ mean projected diameter, a two-spot graticule could be used. We have, however, continued to use the three-spot graticule, sorting particles into four size groups, in order to obtain some indication of the size distribution of the dust. There are indications that simple counting of the number of particles between two limits is not so accurate as when counting is done with some size classification. This is probably because the microscopist concentrates more if he has to classify each particle; he will certainly count rather more 
slowly and in doing so will be able to re-focus continually and to bring into view small particles that are out of focus when a large particle is being examined.

Table 1 illustrates that there is an increase in the total number of particles counted when they are classified in the four size groups. Traverses were made across thermal precipitator records first without sizing and then with sizing, using the threespot graticule.
The graticule described in this paper is made by Messrs. Cooke, Troughton, and Simms and may be obtained on glass discs of either $18 \mathrm{~mm}$. or $21 \mathrm{~mm}$. diameter. It may also be obtained ruled on a groundglass screen for use with the Vickers projection microscope.

\section{REFERENCES}

Beadle, D. G., and Patterson, H. S. (1939). Nature, Lond., $144,327$. See also comment by Ockenden, F. E. J., Ibid., 144, 516.

Fairs, G. Lowrie (1943). Chem. Ind. 62, 374.

May, K. R. (1945). J. sci. Instrum., 22, 187.

Patterson, H. S., and Cawood, W. (1936). Trans. Faraday Soc., 32, 1084. 